\title{
Expression of progerin does not result in an increased mutation rate
}

\author{
Emmanuelle Deniaud • Charlene Lemaître • \\ Shelagh Boyle • Wendy A. Bickmore
}

Received: 10 August 2016 / Revised: 8 April 2017 / Accepted: 13 April 2017 / Published online: 6 May 2017

(C) The Author(s) 2017. This article is an open access publication

\begin{abstract}
In the premature ageing disease HutchinsonGilford progeria syndrome (HGPS), the underlying genetic defect in the lamin A gene leads to accumulation at the nuclear lamina of progerin - a mutant form of lamin A that cannot be correctly processed. This has been reported to result in defects in the DNA damage response and in DNA repair, leading to the hypothesis that, as in normal ageing and in other progeroid syndromes caused by mutation of genes of the DNA repair and DNA damage response pathways, increased DNA damage may be responsible for the premature ageing phenotypes in HGPS patients. However, this hypothesis is based upon the study of markers of the DNA damage response, rather than measurement of DNA damage per se or the consequences of unrepaired DNA damage - mutation. Here, using a mutation reporter cell line, we directly compared the inherent and induced mutation rates in cells expressing wild-type lamin A or progerin. We find no evidence for an elevated mutation rate in progerin-expressing cells. We conclude that the cellular defect in HGPS cells does not lie in the repair of DNA damage per se.
\end{abstract}

Keywords DNA damage $\cdot$ Lamin A - nuclear lamina . progeria

Responsible Editor: Irina Solovei.

E. Deniaud $\cdot$ C. Lemaître $\cdot$ S. Boyle $\cdot$ W. A. Bickmore $(\bowtie)$ MRC Human Genetics Unit, MRC Institute of Genetics and Molecular Medicine, University of Edinburgh, Crewe Road, Edinburgh EH4 2XU, UK

e-mail: Wendy.Bickmore@igmm.ed.ac.uk

\section{Introduction}

Hutchinson-Gilford progeria syndrome (HGPS) is a dominant severe premature ageing genetic disease characterised by the appearance in childhood of agerelated symptoms such as hair loss, thin skin, vascular defects and atherosclerosis. In the majority of cases, the underlying genetic defect is a point mutation that results in activation of a cryptic splice site in exon 11 of lamin $A$ (LMNA) (Eriksson et al., 2003). This leads to accumulation of lamin A protein lacking the 50 amino acid (a.a.) domain toward the C-terminus (LA $\Delta 50$ /progerin) that is required for the final endoproteolytic cleavage step during the normal processing of prelamin A to lamin A. As a consequence, LA $\Delta 50$ remains permanently farnesylated (Cao et al., 2007; Dechat et al., 2007). Mutation of the FACE (Zmpste 24) metalloproteinase, which catalyses the final cleavage step of lamin A processing, results in restrictive dermopathy (RD) that also has progeroid features (Navarro et al., 2004). It is the effect of the aberrantly farnesylated prelamin A proteins on nuclear architecture and nuclear function that is presumed to be responsible for the devastating phenotypes of these progeroid diseases (Mehta et al., 2011; Yang et al., 2011).

At the cellular level, progerin appears to incorporate into the lamina at the nuclear periphery (Eriksson et al., 2003; Goldman et al., 2004). In usual cell culture conditions, the resultant nuclei often develop an abnormal and irregular shape with a thickened lamina, especially as the cells reach later passages. There are also various reports of altered distribution of lamin B (Scaffidi and 
Misteli, 2005), nuclear pores and inner membrane proteins in lamin A mutant cells (Dechat et al., 2007; Scaffidi and Misteli, 2005).

A loss of peripheral electron-dense heterochromatin is seen by electron microscopy (e.m.) in later-passage (p26) HGPS fibroblasts (Goldman et al., 2004). Globally, most HGPS fibroblasts appear to have reduced levels of the heterochromatin protein HP1 $\alpha$ and histone modifications (H3K9me3 and $\mathrm{H} 3 \mathrm{~K} 27 \mathrm{me} 3$ ) associated with heterochromatic states (Dechat et al., 2008; Scaffidi and Misteli, 2005; Shumaker et al., 2006). But genomic profiling in HGPS cells suggests a more complex redistribution of H3K27me3 rather than a simple loss (McCord et al., 2013). H3K9me3 levels in Zmpste 24-deficient cells seem to depend on the passage number (Liu et al., 2013). These chromatin phenotypes are recapitulated in wild-type cells which ectopically express LA $\Delta 50$ (Goldman et al., 2004), but they are not rescued in HGPS cells transfected with wild-type lamin A (Scaffidi and Misteli, 2005). These data serve to underpin the idea that LA $\Delta 50$ acts as a dominant negative, or gain of function, mutation. Indeed, the presence of progerin may interfere with processing of wild-type lamin A (Goldman et al., 2004).

The presence of progerin or unprocessed prelamin A, or indeed the accumulation of farnesylated prelamin A in Zmpste $24^{-1-}$ cells, has been reported to lead to defects in the DNA damage response and in DNA repair and, as a consequence, an increase in DNA damage (Ghosh et al., 2015; Liu et al., 2005; Liu et al., 2006; Liu et al., 2008; Manju et al., 2006; Sedelnikova et al., 2004). This has led to the hypothesis that an accumulation of unrepaired DNA damage may be responsible for the premature ageing phenotypes in HGPS, RD and FACE/Zmpste24 mutants (Agarwal et al., 2003; Bergo et al., 2002). This is consistent with the idea that defective DNA repair and increased DNA damage are causally related to both other progeroid syndromes in which known genes of the DNA repair and DNA damage response pathways are mutated (Kudlow et al., 2007; Niedernhofer et al., 2006; Wijnhoven et al., 2005), and also to normal ageing (Garinis et al., 2008; Musich and Zou, 2009).

How lamin A mutation and lamin A processing defects might result in defective DNA repair is not clear. Because progerin seems to have an increased association with the nuclear lamina and a decreased association with internal lamin A foci, it could sequester replication proteins away from these internal sites (Barbi et al.
2004) leading to stalled and then collapsed replication forks (Barbi et al. 2004; Garinis et al., 2008; Misteli and Scaffidi, 2005; Musich and Zou, 2009). Inappropriate sequestration of repair proteins to these sites of DNA breaks may also be involved (Liu et al., 2008). Increased generation of reactive oxygen species (ROS) has also been reported in progeria fibroblasts (Richards et al., 2011). Finally, organisation at the nuclear periphery, especially of heterochromatin, may be important to physically shield the genome from incoming mutagens (Hsu, 1975).

There is a clear need to better understand the nature of any defect in DNA repair in HGPS. However, with the exception of some comet assays, previous studies have relied upon markers of the DNA damage response (e.g. $\gamma \mathrm{H} 2 \mathrm{~A} . \mathrm{X}$ ), rather than DNA damage per se, to address this question. The consequence of unrepaired DNA damage is mutation. Here, using a mutation reporter cell line derived from Muta ${ }^{\mathrm{TM}}$ Mouse (White et al., 2003), we have directly compared the inherent mutation rate in cells expressing wild-type or LA $\Delta 50$ lamin $\mathrm{A}$ and also the mutation rate induced in these cells by exposure to exogenous mutagens. We find no significant elevation of the mutation rate, scored at the mutation reporter, in LA $\Delta 50$ /progerin-expressing cells and therefore suggest that underlying the cellular defect in HGPS cells does not lie in defective DNA repair per se.

\section{Results}

Expression of wild-type and mutant lamin A in MutaMouse cells

To investigate direct effects of progerin on the repair of DNA damage we took advantage of a well-established mutation reporter system. In the Muta ${ }^{\mathrm{TM} M o u s e, ~ t h e r e ~}$ are $\sim 30$ copies of $\lambda$ gt10lacZ inserted into the mouse genome (Gossen et al., 1989; Shwed et al., 2010) and lac $Z$ then functions as the main target sequence for scoring mutations (Myhr, 1991). A stable epithelial cell line, FE1, was established from these animals and is suitable for measurement of endogenous mutation rates, as well as the rates induced in response to a variety of mutagens (White et al., 2003). To characterise the genomic context of the mutation reporter, we used fluorescence in situ hybridisation (FISH) with a $\lambda$ gt10lacZ probe on metaphase chromosomes from FE1 cells. In each spread, three chromosomes were labelled by the 
probe, and analysis of their DAPI-banding pattern suggested that these might be Mus musculus chromosomes 3 (MMU3). Combined analysis with a chromosome paint for MMU3 confirmed this (Fig. 1a). We conclude that in the aneuploid FE1 cell line ( $n=78$ chromosomes/ spread), there has been a triplication of the original $\lambda$ gt10lacZ-containing chromosome.

To determine the effects of progerin expression on the mutation rate, we created FE1 cell lines stably expressing GFP-tagged human lamin A-either wild type (wt) or $\Delta$ LA50/progerin (Goldman et al., 2004). Ectopic expression of N-terminally GFP-tagged lamin A has been shown to result in the stable integration of the tagged protein into the lamina at the nuclear periphery (Gilchrist et al., 2004). To ensure stable expression from the transgene, we FACs-sorted GFPexpressing cells. Fluorescence microscopy confirmed that both the wt and $\Delta$ LA50 mutant GFP-tagged lamin As concentrate at the nuclear lamina. Optical sectioning along the $z$ axis showed that any bright, apparently
Fig. 1 Expression of mutant and wild-type lamin As in MutaMouse cells. a FISH on metaphase chromosome spread (left) or interphase nucleus (right) from FE1 Muta Mouse cells hybridised with probes for phage $\lambda$ DNA (red) and mouse chromosome 3 (green). DNA is counterstained with DAPI. b Immunofluorescence on parental FE1 cells (left column) and FE1 stable transfectants expressing wild-type (middle column) or $\Delta 50$ (right) mutant lamin A fused to GFP. Confocal mid planes showing GFP fluorescence (top row), immunofluorescence for laminA/C (middle row), merge $(\mathrm{GFP} /$ green, laminA/red and DAPI/blue) (bottom row). Scale bars $=5 \mu \mathrm{m}$. c Western blot of protein extracts from parental FE1 cells (left) and FE1 stable transfectants expressing wild-type $(w t)$ or $\Delta 50$ mutant lamin A fused to GFP, and harvested at various passages. Membranes were probed with antibodies recognising GFP (top row), lamin $\mathrm{A}$ and lamin $\mathrm{C}$ (middle) and PCNA (bottom) — as a loading control
A
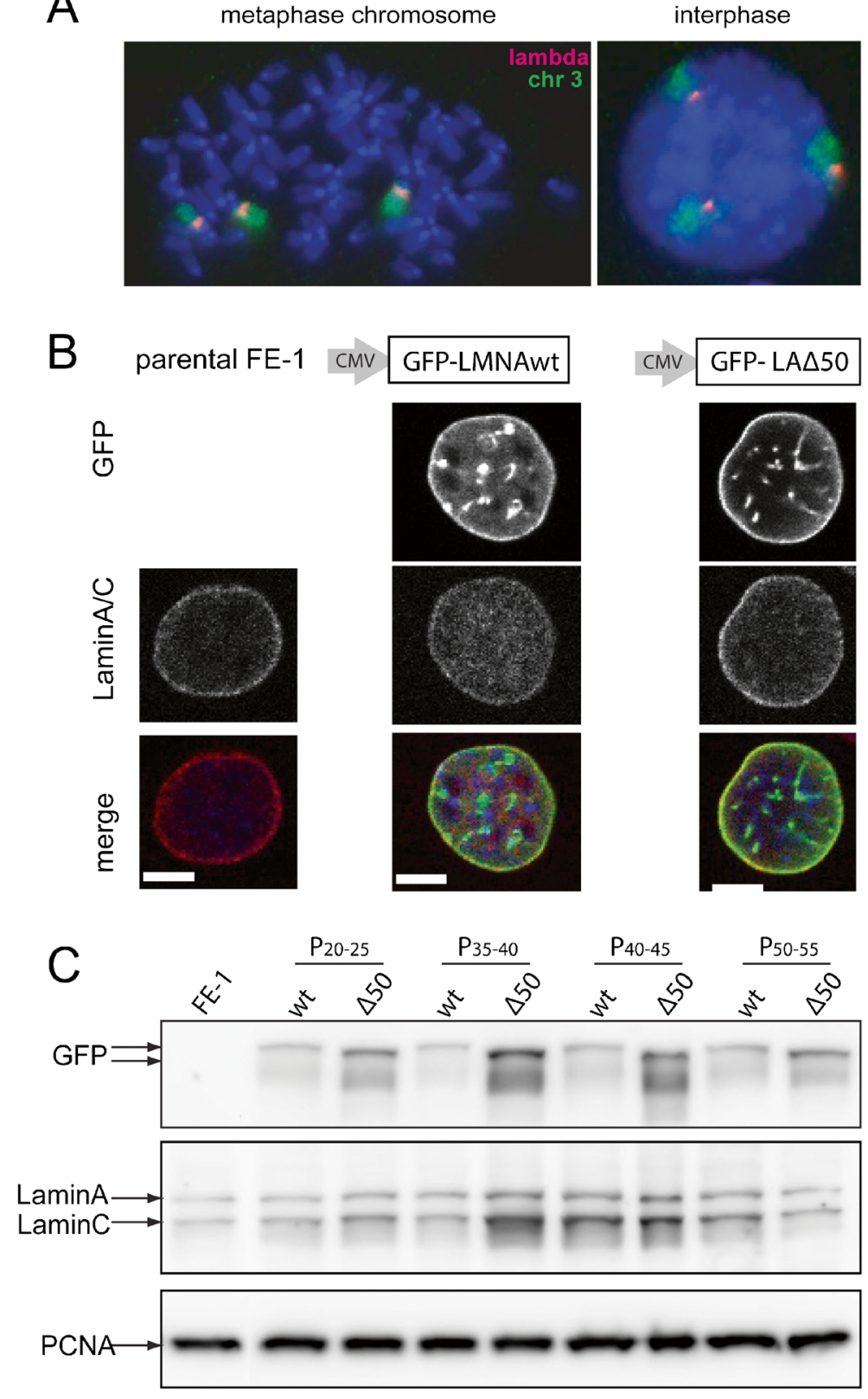

interphase 
internal, foci of GFP-lamin A was due to invaginations of the nuclear periphery (Fig. 1b).

Immunoblotting confirmed the stable expression of the GFP-tagged lamin A over prolonged time in cell culture, with no accompanying obvious decrease in expression of endogenous lamin A (Fig. 1c).

Heterochromatin and nuclear morphology in lamin A-expressing MutaMouse cells

Reduced levels of heterochromatic histone modifications, especially $\mathrm{H} 3 \mathrm{~K} 9 \mathrm{me} 3$, and the heterochromatin protein $1(\mathrm{HP} 1 \alpha)$ that binds to this mark, have been reported in HGPS cells (Scaffidi and Misteli, 2005) and in human cells ectopically expressing $\triangle$ LA50 (Shumaker et al., 2006). By immunoblotting, we saw a small reduction of $\mathrm{H} 3 \mathrm{~K} 9 \mathrm{me} 3$ and $\mathrm{HP} 1 \alpha$ levels in latepassage FE1 cells expressing $\triangle \mathrm{LA} 50$ as compared to cells expressing wild-type lamin A (Fig. 2a), though we did not detect loss of H3K27me3 in the presence of $\triangle \mathrm{LA} 50$.

Another characteristic of HGPS is the acquisition of aberrant nuclear morphology in late-passage cells. Indeed, under normal cell culture conditions in latepassage $\Delta$ LA50-expressing FE-1 cells, we observed that the proportion of cells with aberrant nuclear morphology (evidence of nuclear blebbing, nuclear fragmentation) was $>2.5$-fold higher $(16.4 \%)$ than in FE-1 cells expressing wild-type lamin A (6.1\%) (Fig. 2b). Thus, we conclude that FE-1 transfectants exhibit many of the gross nuclear features reported for HGPS cells and other cells transfected with progerin-expressing constructs and that they therefore represent a suitable model system for studying the effects of $\triangle$ LA50 on DNA damage and mutation.

It is known that mouse cells grown in standard tissue culture conditions - i.e. under high oxygen tension (20\% $\mathrm{O}_{2}$ ) - are subject to oxidative stress and have an elevated mutation rate (Busuttil et al., 2003). Since we wanted to study the effects of $\triangle$ LA50 on intrinsic and induced mutation rates, we did not want to work against a background of mutations introduced as a consequence of nonphysiological culture conditions. Therefore, once established, we maintained the FE-1 cells and the WT and $\triangle$ LA50-expressing FE-1 lines under physiological $\mathrm{O}_{2}(3 \%)$ for multiple passages. The mutation rate of mouse cell lines grown under these conditions is reported to be the same as for primary cells (Busuttil et al., 2003).
Under these conditions, we noted that the proportion of $\Delta$ LA50-expressing cells exhibiting aberrant nuclear morphology was markedly reduced $(10.5 \%)$ relative to the same cells grown in $20 \% \mathrm{O}_{2}$ and was only slightly greater than cells expressing wild-type lamin A (Fig. 2b). Thus, it appears that the aberrant nuclear morphology of lamin A mutant cells may be due to their increased sensitivity to the cell stress of abnormally high $\mathrm{O}_{2}$ concentration. This would be consistent with the increased sensitivity to ROS reported for HGPS fibroblasts (Richards et al., 2011).

Intrinsic mutation rate in the presence of wild-type and mutant lamin $\mathrm{A}$

We first assessed the intrinsic spontaneous mutation rate in lamin A FE1 transfectants by recovery and packaging of $\lambda$ gt10-lacZ genomes from the cellular DNAs of parental FE-1 cells, and cells stably expressing wild-type or $\Delta 50$ lamin A. Resultant phages containing lacZ mutations were selected for by infection of $\mathrm{GalE}^{-}$ E. coli (BIK12001) and plating on minimal agar containing $0.3 \% w / v$ phenyl- $\beta$-D-galactosidase (PGal) (Gossen and Vijg, 1993; Ino et al., 2005). In wild-type $\left(\mathrm{lacZ}^{+}\right.$) phage, release of the galactose moiety from PGal by $\beta$-galactosidase results in the accumulation of toxic UDP-galactose in $\mathrm{GalE}^{-}$strains. Therefore, only cells infected by lac $Z^{-}$mutant phage survive and form plaques (Mientjes et al., 1996) (Fig. 3a). Mutation frequency is then expressed as the ratio of mutant plaques (+PGal plates) to total plaque-forming units (pfu) on non-selective plates. The efficacy of selection was first tested using known wild-type and (L1A15) mutant stocks of $\lambda$ gt10-lacZ phage (Ino et al., 2005). There was a $10^{4}$-fold drop in plating efficiency on PGal selective plates for the wild type over lac $Z^{-}$mutant phage, comparable to previous reports using this system (Ino et al., 2005) (Fig. 3b, c).

Mutant frequency from parental FE-1 cells and lamin A transfectants was then assessed at early $(<\mathrm{P} 24)$ and later (P48-53) passages. The intrinsic mutant frequency of all three cell lines was low $\left(<5.5 \times 10^{-4}\right)$, and there was no evidence for an increase in transfectants stably expressing mutant lamin A $(\Delta 50)(p=0.67)$ (Fig. $3 \mathrm{~d})$. Indeed, there was some evidence that the mutation rate in cells expressing wild-type lamin A was slightly elevated relative to both the parental FE-1 cells and the $\Delta 50$ cell line, but this was not statistically significant. 
Fig. 2 Histone modifications and nuclear morphology in lamin Aexpressing cells. a

Immunoblotting of proteins from FE-1 parental cells and from early $(P 20-25)$ and late (P50-55) passage FE-1 stable transfectants expressing wild-type ( $w t$ ) or $\Delta 50$ mutant lamin $\mathrm{A}$, with antibodies detecting laminA/C, HP1 $\alpha$, H3K9me3 and H3K27me3. H3 and PCNA serve as loading controls. b The table shows the proportion of abnormal nuclei scored in FE-1 transfectants expressing wild-type ( $w t$ ) or $\Delta 50$ mutant GFP-tagged lamin A grown under conditions of low $(3 \%)$ or high $(20 \%) \mathrm{O}_{2}$. $n=$ number of nuclei scored. Below, confocal mid planes show examples of fields of $\Delta 50$ expressing cells grown under conditions of low $(3 \%)$ or high $(20 \%) \mathrm{O}_{2}$. Green = GFP, blue $=$ DAPI. Arrows indicate nuclei scored as abnormal. Scale bars $=5 \mu \mathrm{m}$

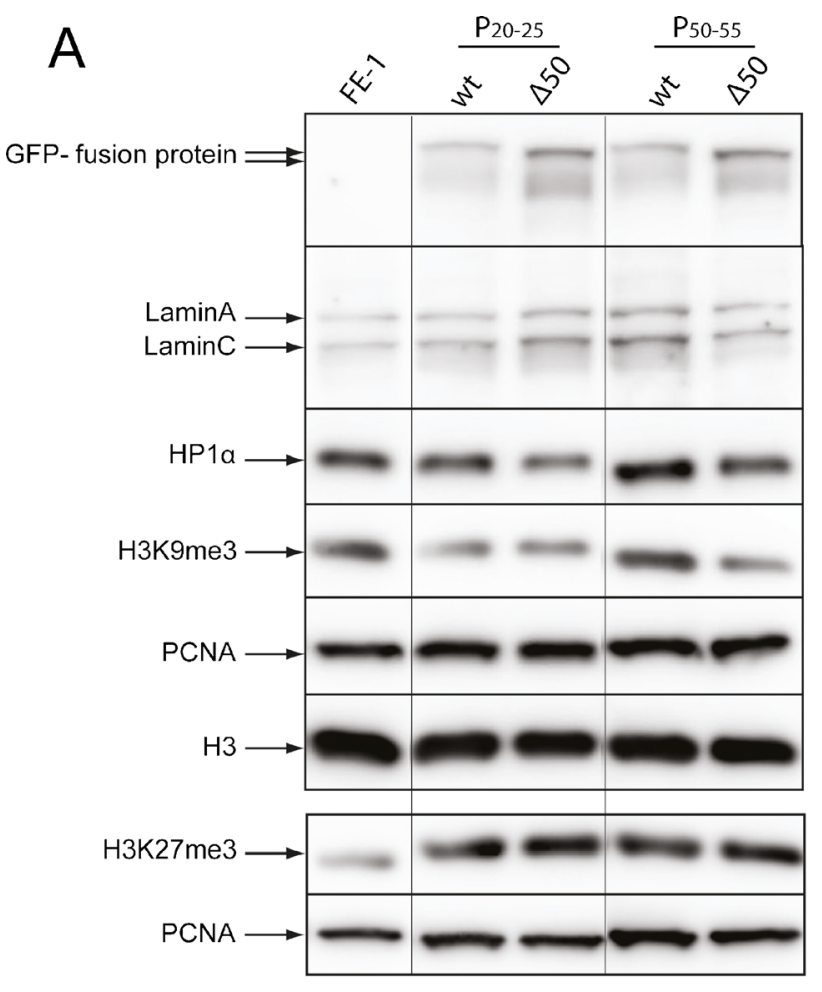

B

\begin{tabular}{|c|c|c|}
\cline { 2 - 3 } \multicolumn{1}{c|}{} & \multicolumn{1}{c|}{$3 \%$ O2 } & \multicolumn{1}{c|}{$20 \%$ O2 } \\
\hline wt & $7.8 \%(n=128)$ & $6.1 \%(n=99)$ \\
\hline$\Delta 50$ & $10.5 \%(n=210)$ & $16.4 \%(n=146)$ \\
\hline
\end{tabular}

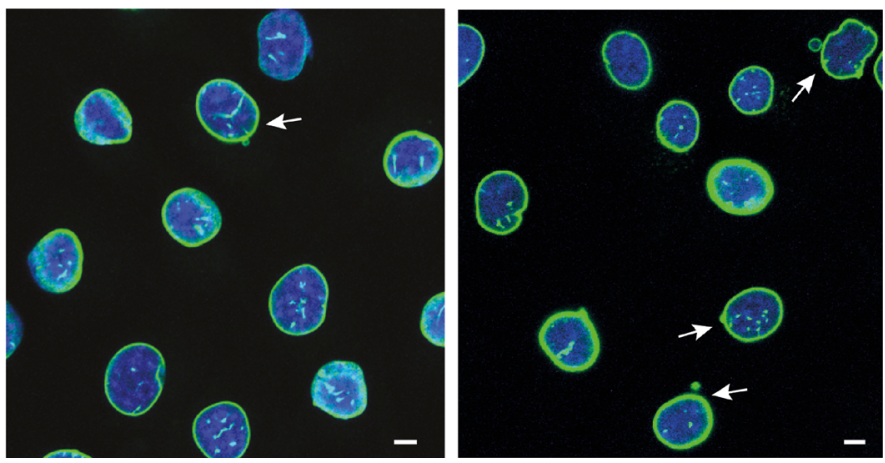

Induced mutant rate in the presence of wild-type and mutant lamin $\mathrm{A}$

To determine if cells expressing mutant lamin A were more susceptible to DNA damage induced by exogenous mutagens, we exposed FE-1 and lamin A transfectants to two different mutagens.

We first analysed the effects of exciting, but non-ionising, UV-C $(254 \mathrm{~nm})$ radiation (Gazave et al., 2005). This induces cyclobutane pyrimidine dimers (CPDs) and strand breaks (Rapp and Greulich, 2004; Turner et al., 2004). Cells were exposed to $10 \mathrm{~J} / \mathrm{m}^{2} \mathrm{UV} 254 \mathrm{~nm}$ on two consecutive days and harvested $72 \mathrm{~h}$ after the first exposure to mutagen. Efficacy of the mutagen was assessed by measuring the frequency of mutant phage particles recovered from parental FE-1 cells before and after treatment. UV-C elevated the mutant frequency 

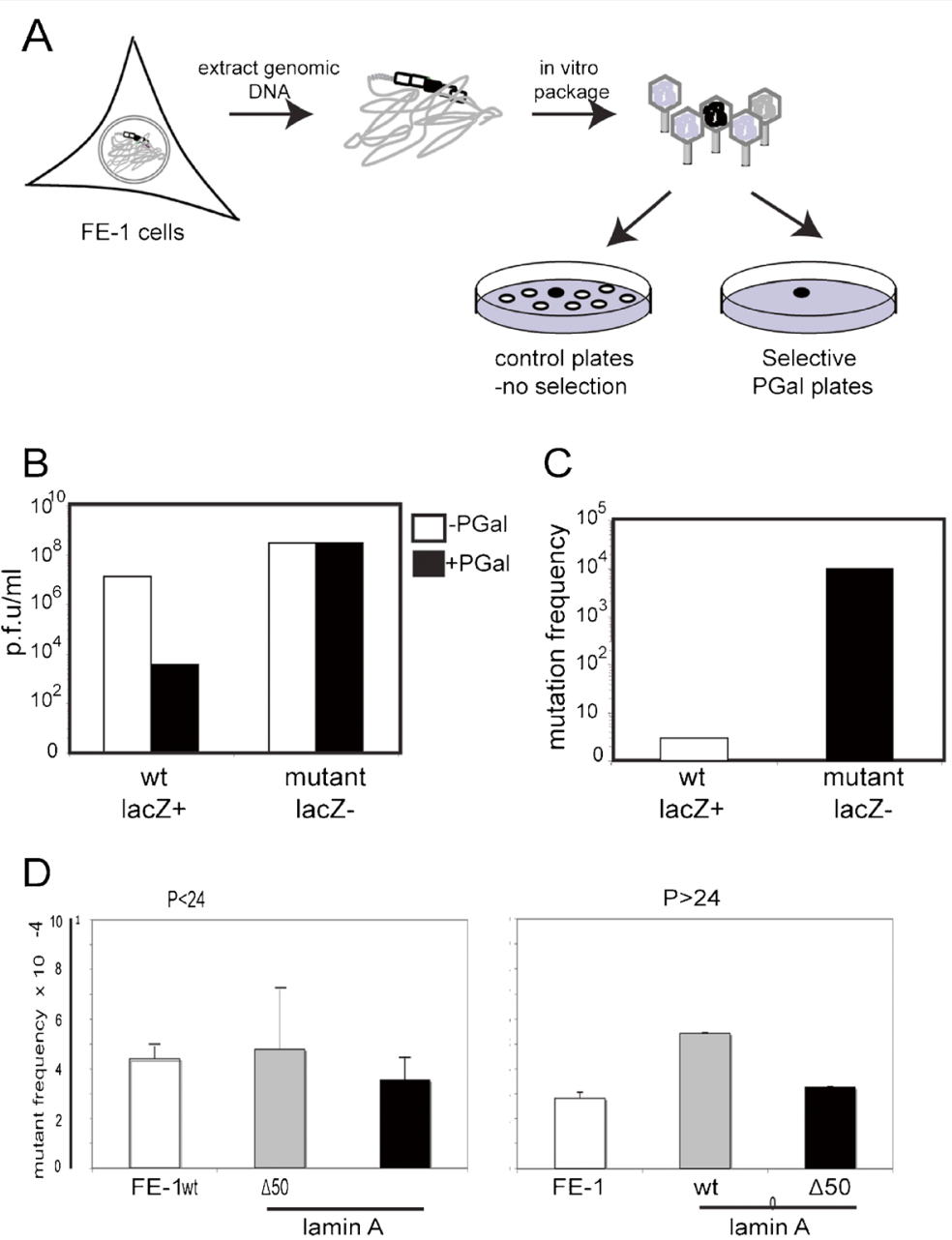

Fig. 3 Determination of intrinsic mutant frequency in lamin Aexpressing cells. a Schematic showing the determination of mutation frequency at $\lambda$ gt10lacZ sequences in FE-1 cells, by in vitro packaging of phage DNA and plating of infected E. coli on PGal selective plates. Only phage with mutations in lacZ (black filled) grow on selective PGal plates. Mutation frequency $=$ ratio of pfu on PGal/pfu on non-selective (-PGal) plates. $\mathbf{b}$ and $\mathbf{c}$ Confirmation of efficacy of PGal selection. b The graph shows plating efficiency (pfu/ml in log scale) of wild-type (lacZ+) and known mutant (LacZ-) phage stocks on selective (+PGal, black bars) and non-

tenfold $\left(p<1 \times 10^{-6}\right)$ (Fig. 4a). UV-C similarly elevated the mutant phage frequency from FE-1 transfectants expressing wild-type or mutant $(\Delta 50)$ lamin A. However, as seen for the intrinsic mutation frequencies, and contrary to what was expected from proposed models of HGPS pathogenesis, the mutant frequency in cells expressing wild-type LMNA appeared a bit higher than in cells expressing LA $\Delta 50$ mutant protein, although overall

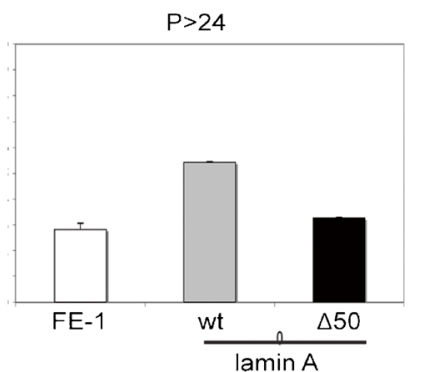

selective (-PGal, white bars) plates. c Mutant frequency (pfu $+\mathrm{PGal} / \mathrm{pfu}-\mathrm{PGal}$ ) measured for wild-type (white bars) and known mutant (LacZ-) stocks of phage. d Mutant frequency $\left(\times 10^{4}\right)$ measured at the $\lambda$ gt10lacZ transgenes in FE-1 cells and in these cells stable expressing wild-type lamin A (wt) and HGPS mutant lamin $\mathrm{A}(\Delta 50)$. Cells were tested at low passage $(<\mathrm{P} 24$, left-hand graph $)$ and then again at higher passage number $(P=48$ 53). The graphs show the mean \pm s.e.m. for genomic DNAs isolated from two independent experiments, and with technical replicates for packaging of these DNAs

this was not statistically significant $(p=0.14)$ (Fig. 4b).

To ascertain whether a similar result could be obtained using a different mutagen with a different mode of action, we treated cells with the alkylating agent ethyl nitrosourea (ENU). ENU induces mainly A:T to T:A transversions, probably due to thymine adducts. We treated FE-1 cells with 0.85 and $1.7 \mathrm{mM}$ $(200 \mu \mathrm{g} / \mathrm{ml}$ in DMSO) ENU, since the latter is the dose 


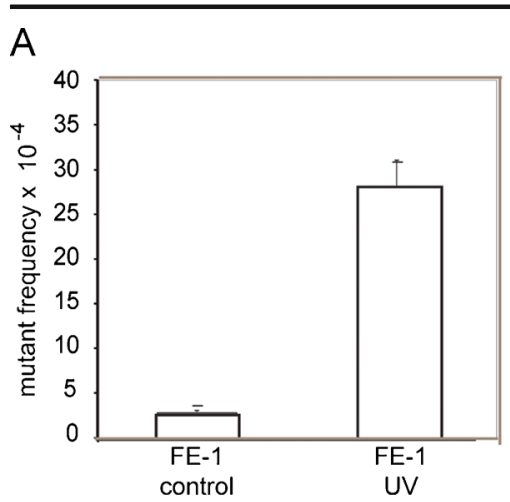

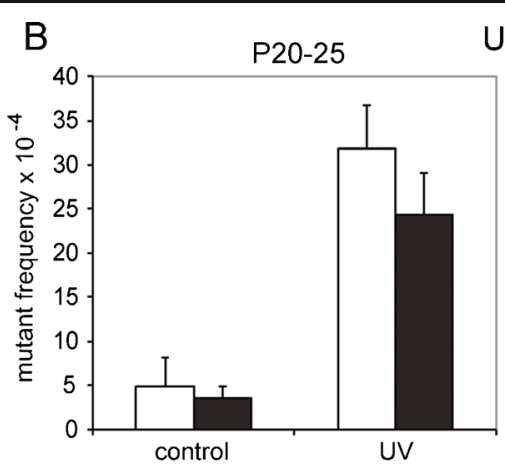

UV -C

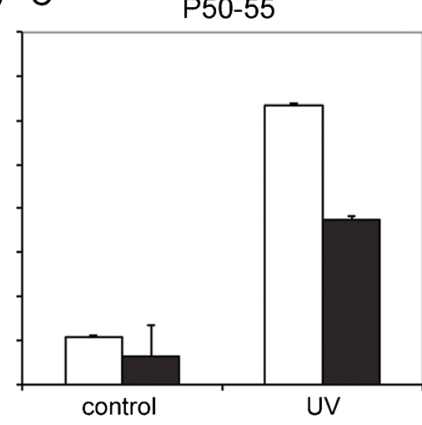

ENU

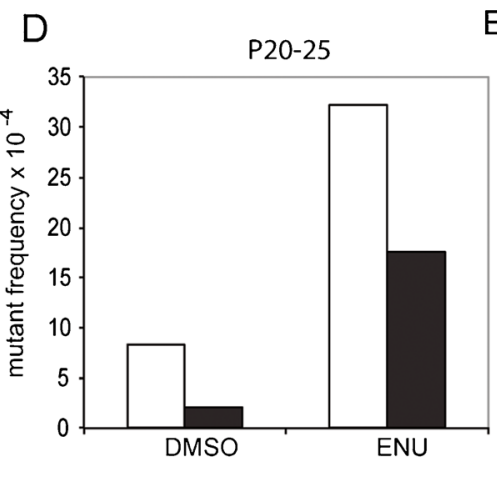

Wt $\triangle 50$
C

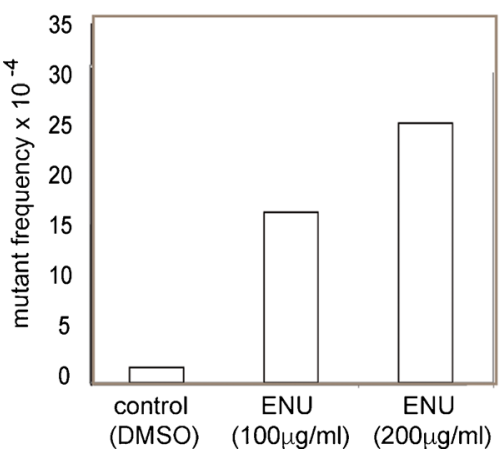

Fig. 4 Induced mutant frequency in wild-type and mutant lamin A-expressing cells. a Mutant frequency $\left(\times 10^{4}\right)$ measured at the $\lambda$ gt10lacZ transgenes in untreated control FE-1 cells and in cells exposed to $10 \mathrm{~J} / \mathrm{m}^{2} \mathrm{UV} 254 \mathrm{~nm}$. b Mutant frequency $\left(\times 10^{4}\right)$ in control and UV-treated FE-1 cells stably expressing wild-type lamin A (wt, white bars) or $\Delta 50$ mutant lamin A (black bars). Cells were tested at low passage $(<\mathrm{P} 24$, left-hand graph $)$ and then again at a higher passage number $(P=48-53)$. The graphs show

reported to produce a maximal mutant rate of $2 \times 10^{-3}$, i.e. $5 \times$ spontaneous rate, at the lacZ reporter from Muta ${ }^{\mathrm{TM} M o u s e}$ (White et al., 2003). Indeed, we saw a similar increase in mutant frequency, compared to DMSO-treated controls, in our assay (Fig. 4c).

The mutant frequency in lamin A-expressing FE-1 stable transfectants was also elevated by ENU treatment, but as was seen for UV treatment, the ENUinduced mutant rate was higher in the cells expressing wild-type lamin A than those expressing $\operatorname{LA} \Delta 50$, and this was statistically significant $\left(p=<1 \times 10^{-4}\right)$ (Fig. 4d). Hence, by scoring for mutant lacZ in transgenic murine cells, we are unable to find any evidence for an increased rate of unrepaired DNA damage caused by the presence of progerin. If anything, the expression of progerin suppressed the mutation frequency, at least in the case of the mutagen ENU. the mean \pm s.e.m. for genomic DNAs isolated from two independent experiments, and with technical replicates for packaging of these DNAs. c Mutant frequency $\left(\times 10^{4}\right)$ measured at the $\lambda$ gt10lacZ transgenes in control (DMSO) FE-1 cells and in cells exposed to 0.85 and $1.7 \mathrm{mM}(100$ and $200 \mu \mathrm{g} / \mathrm{ml})$ ENU. d As in b but for control (DMSO) and $1.7 \mathrm{mM}$ ENU-treated FE-1 cells stably expressing wt or $\Delta 50$ mutant lamin A

No increase in $\gamma \mathrm{H} 2 \mathrm{~A} . \mathrm{X}$ in progerin-expressing cells

An increased appearance of $\gamma \mathrm{H} 2 \mathrm{~A} . \mathrm{X}$ and 53BP1 foci, and defective recruitment of 53BP1 to sites of DNA damage, has been reported in Zmpste24-deficient mouse embryonic fibroblasts (MEFs), in HGPS fibroblasts and in wild-type MEFs expressing unprocessed prelamin A (Liu et al., 2005; Liu et al., 2008), suggesting a perturbed response to DNA damage and compromised DNA repair. To investigate this further, we first showed that the appearance of $\gamma \mathrm{H} 2 \mathrm{~A}$.X foci could indeed be induced by exposure of FE-1 cells to oxidative damage $\left(\mathrm{H}_{2} \mathrm{O}_{2}\right)$ and detected both by immunofluorescence (Fig. 5a) and immunoblotting (Fig. 5c). However, under low- $\mathrm{O}_{2}$ growth conditions, we did not find evidence, by either immunofluorescence (Fig. 5b) or by immunoblotting (Fig. 5d), for elevated levels of $\gamma \mathrm{H} 2 \mathrm{~A} . \mathrm{X}$ in progerin-expressing FE-1 cells. Some 

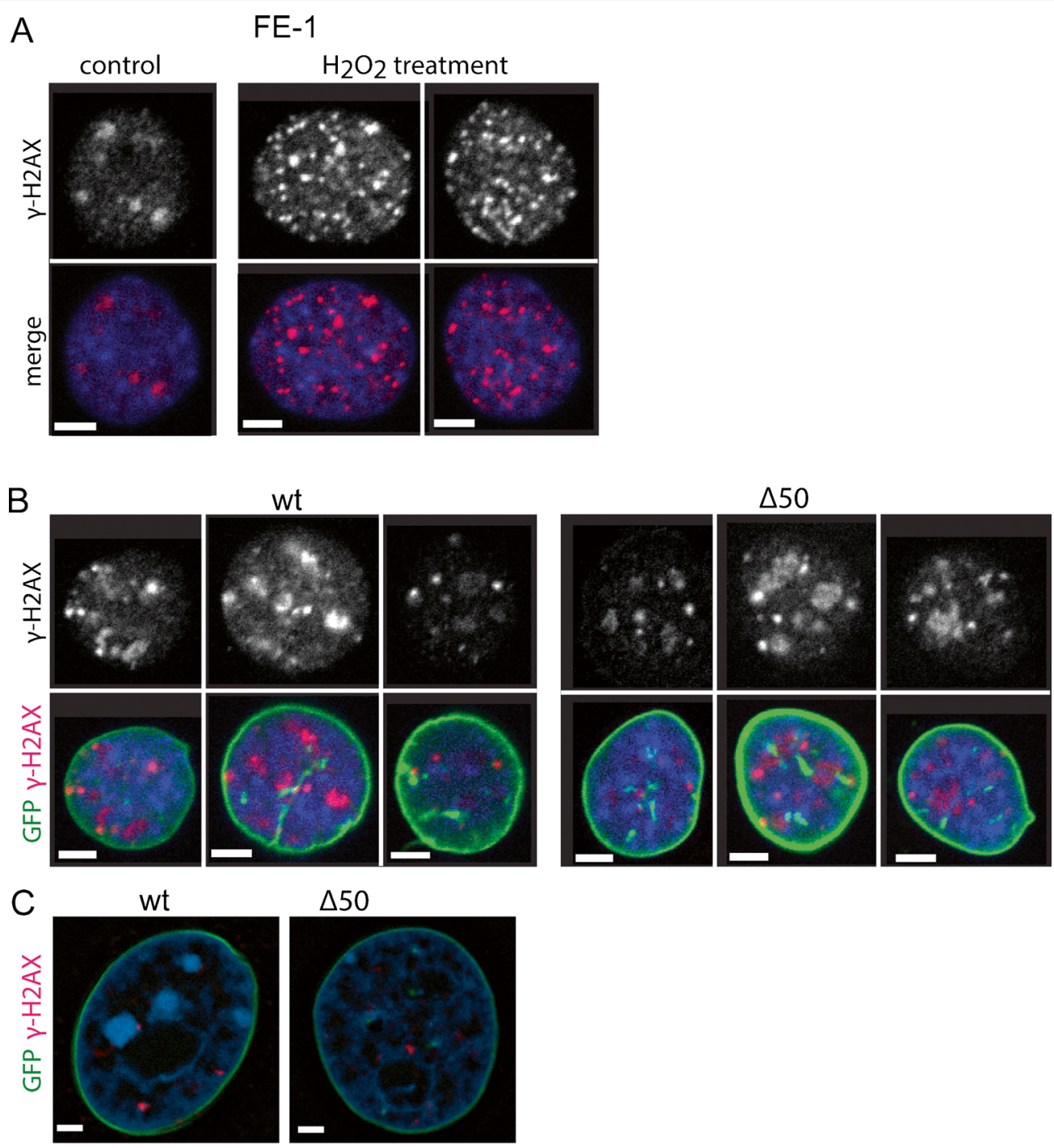

$\Delta 50$

D

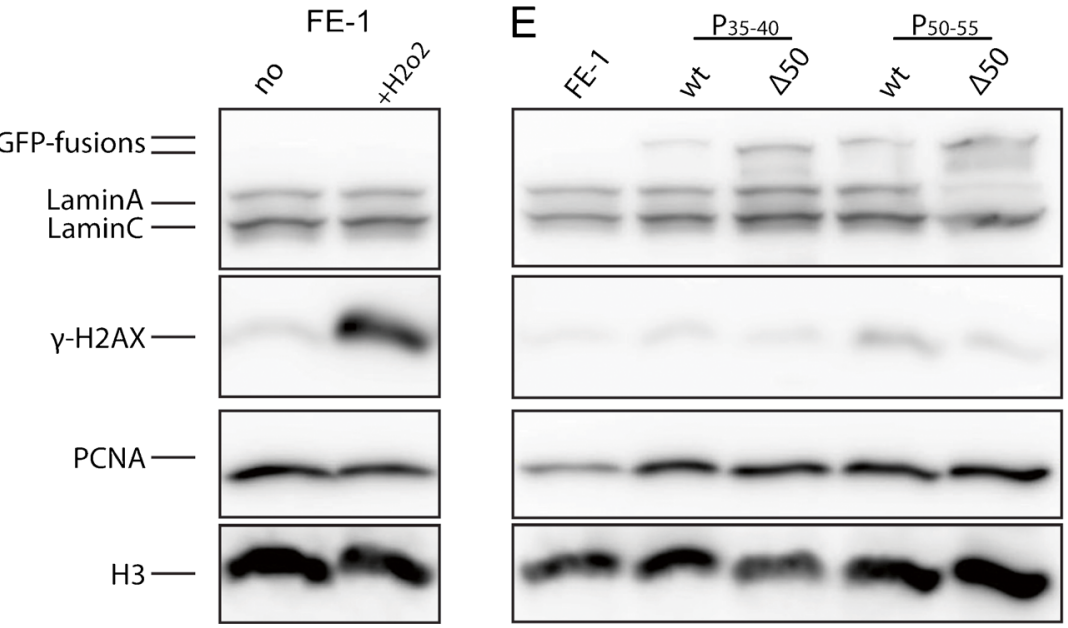


4 Fig. 5 Indicators of the DNA damage response in wild-type and mutant lamin A-expressing cells. a Immunofluorescence with antibody detecting $\gamma \mathrm{H} 2 \mathrm{~A}$.X in FE-1 cells and cells exposed to $1 \mathrm{mM} \mathrm{H}_{2} \mathrm{O}_{2}$ for $25 \mathrm{~min}$. In merge antibody is red, blue = DAPI. Scale bars $=5 \mu \mathrm{m}$. b Immunofluorescence with antibody detecting $\gamma$ H2A.X in FE-1 cells expressing wild-type (wt) or $\Delta 50$ mutant lamin A. In merge antibody is red, green = GFP, blue = DAPI. c Immunofluorescence with antibody detecting yH2A.X (red) in FE-1 cells expressing wild-type (wt) or $\Delta 50$ mutant lamin A. Green = GFP, blue = DAPI. Scale bars $=2 \mu \mathrm{m}$. d Immunoblot with antibodies detecting lamin A/C and $\gamma \mathrm{H} 2 \mathrm{~A} . \mathrm{X}$ in FE- 1 cells and cells exposed to $1 \mathrm{mM} \mathrm{H}_{2} \mathrm{O}_{2}$ for $25 \mathrm{~min}$. PCNA and $\mathrm{H} 3$ serve as loading controls. e Immunoblot with antibodies detecting lamin $\mathrm{A} / \mathrm{C}$ and $\gamma \mathrm{H} 2 \mathrm{~A} . \mathrm{X}$ in FE-1 cells and transfectants expressing wild-type ( $w t)$ or $\Delta 50$ mutant lamin A

increase in $\gamma \mathrm{H} 2 \mathrm{~A} . \mathrm{X}$ was seen with prolonged passage in culture, but this was more pronounced in cells expressing wild-type lamin A than in those expressing the mutant protein. Finally, to assess whether our failure to detect increased levels of DNA damage was due to growth under $3 \% \mathrm{O}_{2}$, we repeated the analysis in cells grown under high $(20 \%) \mathrm{O}_{2}$. As with cells under the lower $\left[\mathrm{O}_{2}\right]$, we observed no evidence for increased foci of $\gamma$ H2A.X (Fig. 5c), or 53BP1 (data not shown) in progerin-expressing FE-1 cells compared to cells expressing wild-type Lamin A.

\section{Discussion}

There is little doubt that the accumulation of damage to cellular components, including DNA, contributes to normal chronological ageing (Li and Vijg, 2012). Both genome instability and point mutations increase with age (Gorbunova et al., 2007). The premature ageing phenotypes seen in many genetic disorders with mutation of genes involved in DNA metabolism reaffirm that DNA damage and a loss of genome integrity is a key feature of both normal and abnormal ageing (Garinis et al., 2008).

The mechanisms that lead to a premature ageing phenotype due to the dominant LA $\Delta 50$ mutation in HGPS are a matter of ongoing debate. However, one plausible mechanism is that there are defects in DNA damage sensing and/or DNA repair (Gonzalo and Kreienkamp, 2015). Studies that have addressed this possible mechanism have examined markers of the DNA damage response and DNA repair pathways. However, compromised sensing or repair of DNA damage should lead to an increase in unrepaired DNA damage-i.e. mutation. This has been inferred (Liu et al., 2008) but not previously directly assessed, in HGPS cells or in cells expressing progerin (LA $\Delta 50)$. Here, we have used transgenic reporter cell lines to directly investigate the effects of LA $\Delta 50$ mutant lamin A on the spontaneous and induced mutation rate of the phage mutation reporter integrated into the genome of these cell lines (Fig. 1). Such transgenic mutation reporters have been used to reveal the accumulation of mutation load during chronological ageing (Busuttil et al., 2007; Dolle et al., 1997; Dolle et al., 2000) but, to our knowledge, have not previously been used to assess the role of nuclear structure on DNA damage.

We found no evidence for an increase in the spontaneous mutation rate (Fig. 3) in cells expressing human progerin mutant lamin A compared with cells expressing wild-type lamin A. Many different DNA repair pathways are mutated in other progeria syndromes, and all DNA repair pathways seem to decline with chronological ageing (Gorbunova et al., 2007). The mutagens that we have investigated here (UV and ENU) likely are targeted by global-genome nucleotide excision repair (NER), base excision repair (BER) and break repair. NER is a 'detect-excise-and-patch' repair system for a broad class of helix-distorting lesions such as UV-induced photoproducts and many bulky chemical adducts. The global-genome NER pathway detects such lesions anywhere in the genome, whereas the transcription-coupled NER (TC-NER) pathway is selective for lesions that block transcriptional elongation. UV-induced CPD photoproduct removal is reduced in older and senescent fibroblasts (Boyle et al., 2005; Gorbunova et al., 2007), especially in the nontranscribed region (Gonzalo and Kreienkamp, 2015; Guo et al., 1998), and BER activity is reported to be decreased in old mice (Busuttil et al., 2007; Intano et al., 2003). Similarly, MEFS from lamina-associated progeroid syndromes are reported to be hypersensitive to UV (Liu et al., 2005). We did score a significantly elevated mutant rate at FE-1 cells and transfectants after their exposure to either UV or ENU; however, this induced mutant rate was no higher in FE-1 transfectants expressing LA $\Delta 50$ than in the parental cells or cells expressing wt lamin A (Fig. 4).

Because we have only scored mutation at an unexpressed reporter locus (LacZ), we cannot exclude that it is specifically transcription-coupled repair that is affected in HGPS, though no increase in the spontaneous mutation rate has been seen in progeroid TC-NER mutants 
(Wijnhoven et al., 2007). Similarly, since not all tissues seem to age prematurely in HGPS, it is possible that the FE-1 cell line is not from a suitable tissue type to reveal a defect in DNA repair caused by expression of LA $\Delta 50$ (Martin and Oshima, 2000).

As has been previously reported (Dechat et al., 2007, Goldman et al., 2004, Shumaker et al., 2006), we found an increased proportion of abnormally and irregularly shaped nuclei in cells expressing LA $\Delta 50$ mutant as compared to wt lamin A (Fig. 2). However, we noticed a decrease in this proportion when LA $\Delta 50$-expressing cells were grown at physiological oxygen levels (3\%) as compared to the $20 \% \mathrm{O}_{2}$ of standard tissue culture. A similar decrease in aberrant nuclear morphology was not seen in cells expressing wt lamin A. This suggests that progerin-expressing cells may be especially sensitive to oxidative stress, and this is consistent with the elevated levels of reactive oxygen species reported in HGPS cells (Richards et al., 2011; Viteri et al., 2010).

Materials and methods

FE1 Muta ${ }^{\mathrm{TM}}$ Mouse lung epithelial cells were cultured as described by White et al. (2003). Briefly, cells were cultured in 1:1 DMEM/F12 nutrient mixture (Invitrogen) supplemented with 2\% FBS (Sigma), $2 \mathrm{mM}$ glutamine and $1 \mathrm{ng} / \mathrm{ml}$ murine epidermal growth factor (Invitrogen). Cells were maintained at $37^{\circ} \mathrm{C}$ in hypoxic incubators (New Brunswick Galaxy 170R) with $3 \% \mathrm{O}_{2}$ or in atmospheric- $\mathrm{O}_{2}$-level incubators when indicated. For hydrogen peroxide $\left(\mathrm{H}_{2} \mathrm{O}_{2}\right)$ treatment, cells were exposed to $1 \mathrm{mM} \mathrm{H}_{2} \mathrm{O}_{2}$ for $25 \mathrm{~min}$.

\section{FISH}

Cells were swollen in $0.56 \% \mathrm{KCl}$ before fixation in $3: 1$ methanol/acetic acid. Slides were incubated with $100 \mu \mathrm{g} / \mathrm{ml}$ RNaseA in $2 \times \mathrm{SSC}$ for $1 \mathrm{~h}$, washed in $2 \times$ SSC and dehydrated through an alcohol series. Slides were then denatured in $70 \%$ formamide $/ 2 \times \mathrm{SSC}$ for $1 \mathrm{~min}$. $\lambda$ DNA was purified using the manufacturer's protocol (Qiagen, \# 12543) and labelled by nick translation with digoxigenin-11-dUTP (Morey et al., 2007). Approximately $100 \mathrm{ng}$ of labelled DNA probe and $15 \mu \mathrm{l}$ of FITC-mouse chromosome-3 paint (Cambio) were used per slide, together with $5 \mu \mathrm{g}$ of mouse Cot1 DNA (GIBCO BRL) and $5 \mu \mathrm{g}$ salmon sperm DNA. Probes were denatured at $70{ }^{\circ} \mathrm{C}$ for $5 \mathrm{~min}$, reannealed with Cot1 DNA for $15 \mathrm{~min}$ at $37^{\circ} \mathrm{C}$ and hybridised to the denatured slides overnight. Digoxigenin-labelled probes were detected with Texas-Red anti-sheep (Vector). Slides were counterstained with $0.5 \mu \mathrm{g} / \mathrm{ml}$ 4',6'-diamidino-2-phenylindole (DAPI) in Vectashield.

Cloning and expression of lamin A and LAD50

Stable FE-1 cells were prepared expressing either EGFP-myc-LA or EGFP-myc-hLA $\Delta 50$. The coding regions from pTRE-EGFP-myc-hLMNA or hLMNA $\Delta 50$ (Goldman et al., 2004; Shumaker et al., 2006) were excised as a $2.8-\mathrm{kb}$ BamHI/XbaI fragment and cloned into pcDNA3.1 (+) (Invitrogen). The resulting plasmids (pcDNA-EGFP-myc-hLMNA and pcDNA-EGFP-myc-hLMNA $\Delta 50$ ) were linearised with ScaI and transfected into FE-1 cells by lipofectamine 2000 (Invitrogen). After 48 h, cells were trypsinised and GFP-expressing cells sorted using a BD FACSAriaII SORP instrument (Becton Dickinson). The 488-nm laser was used for measuring forward scatter, side scatter and GFP fluorescence (525/50 nm bandpass filter). BD FACSDiva software (Becton Dickinson, Version 6.1.2) was used for instrument control and data analysis. The purified GFP-expressing cells were seeded in a six-well plates and expanded. Cell populations were sorted regularly for GFP fluorescence to maintain a high proportion of GFP-lamin A-expressing cells. After establishment of stably expressing cell lines, cells were maintained in a $3 \% \mathrm{O}_{2}$ incubator.

Immunofluorescence

Cells grown on coverslips were fixed in $4 \%$ paraformaldehyde in PBS and permeabilised in $0.2 \%$ Triton X-100/ PBS for $12 \mathrm{~min}$. Fixed cells were incubated overnight at $4{ }^{\circ} \mathrm{C}$ with primary antibodies against Lamin $\mathrm{A} / \mathrm{C}(1: 100$, Cell Signalling) or $\gamma$-H2AX phospho-[Ser139] (1:100, \#05-636 Millipore). The slides were then incubated for $1 \mathrm{~h}$ at room temperature with Alexa-Fluor 488 or AlexaFluor 594 secondary antibodies (1:1000, Invitrogen). Cells were counterstained with $0.02 \mu \mathrm{g} / \mathrm{ml}$ DAPI in PBS and mounted in Vectashield. Slides were examined on a Nikon A1R confocal microscope equipped with a CFI Plan Fluor $\times 40 / 1.30$ oil objective and NIS elements software.

Western blotting

Western blot analysis was carried out using standard protocols. Immunoblotting was performed with primary 
antibodies directed against Lamin A/C (1:2000, \#sc6215, Santa-Cruz Biotechnology) or (1:1000, \#4777, Cell Signalling), GFP (1:2000, \#11-814-460-001 Roche), H3K27me3 (1:2000, \#07-449 Millipore), H3K9me3 (1:1000, \#05-1242 Millipore), $\gamma$-H2AX phospho-[Ser139] (1:500, \#05-636 Millipore), HP1 $\alpha$ (1:500, \#05-689 Millipore), PCNA (1:20,000, \#sc-56 Santa-Cruz Biotechnologies) and H3 (1:50,000, Millipore). Blots were detected by horseradish peroxidase (HRP)-conjugated donkey anti-rabbit, anti-mouse or anti-goat whole molecule $\operatorname{IgG}(1: 10,000)$ and chemiluminescence using ChemiGlow West (Alpha Innotech). Signal was analysed using ImageQuantTL LAS4010 (Version 1; GE Healthcare).

Measurement of LacZ mutant frequency

$3 \times 10^{5}$ cells were cultured in a $100-\mathrm{mm}$ culture dish overnight. For UV-C treatment, cells were washed with PBS and exposed to $10 \mathrm{~J} / \mathrm{m}^{2}$ (UV Stratalinker 1800 , Stratagene) at $254 \mathrm{~nm}$, which was repeated the following day. Cells were collected $72 \mathrm{~h}$ after the first exposure to mutagen. For $N$-ethyl- $N$-nitrosourea (ENU, Sigma) treatment, cells were incubated for $6 \mathrm{~h}$ in serum-free medium containing $200 \mu \mathrm{g} / \mathrm{ml}$ ENU diluted in DMSO, washed with PBS and then incubated for $72 \mathrm{~h}$ with complete medium. Cells were lysed for $3 \mathrm{~h}$ at $55^{\circ} \mathrm{C}$ in $100 \mathrm{mM}$ Tris $\mathrm{pH}$ 8, $200 \mathrm{mM} \mathrm{NaCl}, 5 \mathrm{mM}$ EDTA, $0.2 \%$ SDS and $0.1 \mathrm{mg} / \mathrm{ml}$ proteinase $\mathrm{K}$. DNA was extracted with phenol/chloroform (1:1), followed by chloroform and precipitated by isopropanol, and resuspended in $25 \mu \mathrm{l}$ of TE.

$\lambda$ gt10lacZ DNAs were rescued from FE1 genomic DNA using the Transpack ${ }^{\mathrm{TM}}$ lambda packaging system (Stratagene) according the manufacturer's instructions. The phage preparation was used to infect $E$. coli galE ${ }^{-}$cells prepared in $10 \mathrm{mM} \mathrm{MgSO}_{4}$ at an OD600nm $=2$. The LacZ mutant frequency was determined by using the PGal-positive selection assay (Gossen and Vijg, 1993). Briefly, $100 \mu$ packaged phage particles were incubated with $0.5 \mathrm{ml}$ of host bacterium for $20 \mathrm{~min}$ at $37^{\circ} \mathrm{C}$ and plated on agar containing $0.3 \% \mathrm{w} / \mathrm{v}$ phenyl $\beta$-D-galactoside (PGal, Sigma, \# P6501). After incubation overnight at $37^{\circ} \mathrm{C}$, the number of LacZ mutant plaque-forming units (pfu) was counted. Concurrent pfu titres on non-selective agar were employed to calculate total pfu. Mutant frequency is expressed as the ratio of pfu of PGal: total pfu (no PGal). The statistical significance of differences in mutant frequency scored between cell lines was assessed using $t$ tests.

a.a, amino acid; BER, base excision repair; CPD, cyclobutane pyrimidine dimer; DMSO, dimethyl sulfoxide; e.m., electron microscopy; ENU, ethyl nitrosourea; FISH, fluorescence in situ hybridisation; HGPS, Hutchinson-Gilford progeria syndrome; HRP, horseradish peroxidase; MEF, mouse embryonic fibroblasts; NER, nucleotide excision repair; PGal, phenyl- $\beta$-D-galactosidase; pfu, plaque-forming units; $\mathrm{RD}$, restrictive dermopathy; ROS, reactive oxygen species; TC-NER, transcription-coupled NER; wt, wild type

Acknowledgements This work was supported by an ERC advanced grant (no. 249956) and by a Medical Research Council, UK, Unit Programme grant U127527202. We thank Elisabeth Freyer (MRC HGU technical services) for FACs sorting. We are grateful to Bob Goldman (Northwestern University, Chicago) for the gift of lamin A constructs and to Ichizo Kobayashi and Naofumi Handa (University of Tokyo) for wild-type and mutant Agt10lacZ phage stocks. The FE1 cell line from Muta ${ }^{\mathrm{TM} M o u s e}$ and GalE-E. coli were provided by Health Canada, Ottawa (Paul White and George Douglas). We are also grateful to Paul White (Health Canada) for helpful comments on the manuscript.

Open Access This article is distributed under the terms of the Creative Commons Attribution 4.0 International License (http:// creativecommons.org/licenses/by/4.0/), which permits unrestricted use, distribution, and reproduction in any medium, provided you give appropriate credit to the original author(s) and the source, provide a link to the Creative Commons license, and indicate if changes were made.

\section{References}

Agarwal AK, Fryns JP, Auchus RJ, Garg A (2003) Zinc metalloproteinase, ZMPSTE24, is mutated in mandibuloacral dysplasia. Hum Mol Genet 12:1995-2001

Barbie DA, Kudlow BA, Frock R, Zhao J, Johnson BR, Dyson N, Harlow E, Kennedy BK (2004) Nuclear reorganization of mammalian DNA synthesis prior to cell cycle exit. Mol Cell Biol 24:595-607

Bergo MO, Gavino B, Ross J, Schmidt WK, Hong C, Kendall LV, Mohr A, Meta M, Genant H, Jiang Y et al (2002) Zmpste24 deficiency in mice causes spontaneous bone fractures, muscle weakness, and a prelamin A processing defect. Proc Natl Acad Sci U S A 99:13049-13054

Boyle J, Kill IR, Parris CN (2005) Heterogeneity of dimer excision in young and senescent human dermal fibroblasts. Aging Cell 4:247-255

Busuttil RA, Rubio M, Dolle ME, Campisi J, Vijg J (2003) Oxygen accelerates the accumulation of mutations during the senescence and immortalization of murine cells in culture. Aging Cell 2:287-294 
Busuttil RA, Garcia AM, Reddick RL, Dolle ME, Calder RB, Nelson JF, Vijg J (2007) Intra-organ variation in age-related mutation accumulation in the mouse. PLoS One 2:e876

Cao K, Capell BC, Erdos MR, Djabali K, Collins FS (2007) A lamin A protein isoform overexpressed in HutchinsonGilford progeria syndrome interferes with mitosis in progeria and normal cells. Proc Natl Acad Sci U S A 104:4949-4954

Dechat T, Shimi T, Adam SA, Rusinol AE, Andres DA, Spielmann HP, Sinensky MS, Goldman RD (2007) Alterations in mitosis and cell cycle progression caused by a mutant lamin A known to accelerate human aging. Proc Natl Acad Sci U S A 104:4955-4960

Dechat T, Pfleghaar K, Sengupta K, Shimi T, Shumaker DK, Solimando L, Goldman RD (2008) Nuclear lamins: major factors in the structural organization and function of the nucleus and chromatin. Genes Dev 22:832-853

Dolle ME, Giese H, Hopkins CL, Martus HJ, Hausdorff JM, Vijg J (1997) Rapid accumulation of genome rearrangements in liver but not in brain of old mice. Nat Genet 17:431-434

Dolle ME, Snyder WK, Gossen JA, Lohman PH, Vijg J (2000) Distinct spectra of somatic mutations accumulated with age in mouse heart and small intestine. Proc Natl Acad Sci U S A 97:8403-8408

Eriksson M, Brown WT, Gordon LB, Glynn MW, Singer J, Scott L, Erdos MR, Robbins CM, Moses TY, Berglund P et al (2003) Recurrent de novo point mutations in lamin A cause Hutchinson-Gilford progeria syndrome. Nature 423:293-298

Garinis GA, van der Horst GT, Vijg J, Hoeijmakers JH (2008) DNA damage and ageing: new-age ideas for an age-old problem. Nat Cell Biol 10:1241-1247

Gazave E, Gautier P, Gilchrist S, Bickmore WA (2005) Does radial nuclear organisation influence DNA damage? Chromosom Res 13:377-388

Ghosh S, Liu B, Wang Y, Hao Q, Zhou Z (2015) Lamin A is an endogenous SIRT6 activator and promotes SIRT6-mediated DNA repair. Cell Rep 13:1396-1406

Gilchrist S, Gilbert N, Perry P, Ostlund C, Worman HJ, Bickmore WA (2004) Altered protein dynamics of disease-associated lamin A mutants. BMC Cell Biol 5:46

Goldman RD, Shumaker DK, Erdos M, Eriksson M, Goldman AE, Gordon LB, GruenbaumY KS, Mendez M, Varga R, Collins FS (2004) Accumulation of mutant lamin A causes progressive changes in nuclear architecture in HutchinsonGilford progeria syndrome. Proc Natl Acad Sci U S A 101: 8963-8968

Gonzalo S, Kreienkamp R (2015) DNA repair defects and genome instability in Hutchinson-Gilford progeria syndrome. Curr Opin Cell Biol 34:75-83

Gorbunova V, Seluanov A, Mao Z, Hine C (2007) Changes in DNA repair during aging. Nucleic Acids Res 35:7466-7474

Gossen JA, Vijg J (1993) A selective system for lacZ-phage using a galactose-sensitive E. coli host. BioTechniques 14(326):330

Gossen JA, de Leeuw WJ, Tan CH, Zwarthoff EC, Berends F, Lohman PH, Knook DL, Vijg J (1989) Efficient rescue of integrated shuttle vectors from transgenic mice: a model for studying mutations in vivo. Proc Natl Acad Sci U S A 86: 7971-7975

Guo Z, Heydari A, Richardson A (1998) Nucleotide excision repair of actively transcribed versus nontranscribed DNA in rat hepatocytes: effect of age and dietary restriction. Exp Cell Res 245:228-238

Hsu TC (1975) A possible function of constitutive heterochromatin: the bodyguard hypothesis. Genetics 79(Suppl):137-150

Ino A, Naito Y, Mizuguchi H, Handa N, Hayakawa T, Kobayashi I (2005) A trial of somatic gene targeting in vivo with an adenovirus vector. Genet Vaccines Ther 3:8

Intano GW, Cho EJ, McMahan CA, Walter CA (2003) Age-related base excision repair activity in mouse brain and liver nuclear extracts. J Gerontol A Biol Sci Med Sci 58:205-211

Kudlow BA, Kennedy BK, Monnat RJ Jr (2007) Werner and Hutchinson-Gilford progeria syndromes: mechanistic basis of human progeroid diseases. Nat Rev Mol Cell Biol 8:394-404

Li W, Vijg J (2012) Measuring genome instability in aging. Gerontology 58:129-138

Liu B, Wang J, Chan KM, Tjia WM, Deng W, Guan X, Huang JD, Li KM, Chau PY, Chen DJ et al (2005) Genomic instability in laminopathy-based premature aging. Nat Med 11:780-785

Liu Y, Rusinol A, Sinensky M, Wang Y, Zou Y (2006) DNA damage responses in progeroid syndromes arise from defective maturation of prelamin A. J Cell Sci 119:4644-4649

Liu Y, Wang Y, Rusinol AE, Sinensky MS, Liu J, Shell SM, Zou Y (2008) Involvement of xeroderma pigmentosum group A (XPA) in progeria arising from defective maturation of prelamin A. FASEB J 22:603-611

Liu B, Wang Z, Zhang L, Ghosh S, Zheng H, Zhou Z (2013) Depleting the methyltransferase Suv39h1 improves DNA repair and extends lifespan in a progeria mouse model. Nat Commun 4:1868

Manju K, Muralikrishna B, Parnaik VK (2006) Expression of disease-causing lamin A mutants impairs the formation of DNA repair foci. J Cell Sci 119:2704-2714

Martin GM, Oshima J (2000) Lessons from human progeroid syndromes. Nature 408:263-266

McCord RP, Nazario-Toole A, Zhang H, Chines PS, Zhan Y, Erdos MR, Collins FS, Dekker J, Cao K (2013) Correlated alterations in genome organization, histone methylation, and DNA-lamin A/C interactions in Hutchinson-Gilford progeria syndrome. Genome Res 23:260-269

Mehta IS, Eskiw CH, Arican HD, Kill IR, Bridger JM (2011) Farnesyltransferase inhibitor treatment restores chromosome territory positions and active chromosome dynamics in Hutchinson-Gilford progeria syndrome cells. Genome Biol 12:R74

Mientjes EJ, Steenwinkel MJ, van Delft JH, Lohman PH, Baan RA (1996) Comparison of the X-gal- and P-gal-based systems for screening of mutant lambda lacZ phages originating from the transgenic mouse strain 40.6. Mutat Res 360:101-106

Misteli T, Scaffidi P (2005) Genome instability in progeria: when repair gets old. Nat Med 11:718-719

Morey C, Da Silva NR, Perry P, Bickmore WA (2007) Nuclear reorganisation and chromatin decondensation are conserved, but distinct, mechanisms linked to Hox gene activation. Development 134:909-919

Musich PR, Zou Y (2009) Genomic instability and DNA damage responses in progeria arising from defective maturation of prelamin A. Aging (Albany NY) 1:28-37

Myhr BC (1991) Validation studies with Muta Mouse: a transgenic mouse model for detecting mutations in vivo. Environ Mol Mutagen 18:308-315 
Navarro CL, De Sandre-Giovannoli A, Bernard R, Boccaccio I, Boyer A, Genevieve D, Hadj-Rabia S, Gaudy-Marqueste C, Smitt HS, Vabres P et al (2004) Lamin A and ZMPSTE24 (FACE-1) defects cause nuclear disorganization and identify restrictive dermopathy as a lethal neonatal laminopathy. Hum Mol Genet 13:2493-2503

Niedernhofer LJ, Garinis GA, Raams A, Lalai AS, Robinson AR, Appeldoorn E, Odijk H, Oostendorp R, Ahmad A, van Leeuwen $\mathrm{W}$ et al (2006) A new progeroid syndrome reveals that genotoxic stress suppresses the somatotroph axis. Nature 444:1038-1043

Rapp A, Greulich KO (2004) After double-strand break induction by UV-A, homologous recombination and nonhomologous end joining cooperate at the same DSB if both systems are available. J Cell Sci 117:4935-4945

Richards SA, Muter J, Ritchie P, Lattanzi G, Hutchison CJ (2011) The accumulation of un-repairable DNA damage in laminopathy progeria fibroblasts is caused by ROS generation and is prevented by treatment with $\mathrm{N}$-acetyl cysteine. Hum Mol Genet 20:3997-4004

Scaffidi P, Misteli T (2005) Reversal of the cellular phenotype in the premature aging disease Hutchinson-Gilford progeria syndrome. Nat Med 11:440-445

Sedelnikova OA, Horikawa I, Zimonjic DB, Popescu NC, Bonner WM, Barrett JC (2004) Senescing human cells and ageing mice accumulate DNA lesions with unrepairable doublestrand breaks. Nat Cell Biol 6:168-170

Shumaker DK, Dechat T, Kohlmaier A, Adam SA, Bozovsky MR, Erdos MR, Eriksson M, Goldman AE, Khuon S, Collins FS et al (2006) Mutant nuclear lamin A leads to progressive alterations of epigenetic control in premature aging. Proc Natl Acad Sci U S A 103:8703-8708

Shwed PS, Crosthwait J, Douglas GR, Seligy VL (2010) Characterisation of Muta ${ }^{\mathrm{TM}}$ Mouse $\lambda$ gt10-lacZ transgene: evidence for in vivo rearrangements. Mutagenesis 25:609-616

Turner DP, Yeung AT, Bellacosa A (2004) Ultraviolet irradiation of cells. Methods Mol Biol 285:133-137

Viteri G, Chung YW, Stadtman ER (2010) Effect of progerin on the accumulation of oxidized proteins in fibroblasts from Hutchinson Gilford progeria patients. Mech Ageing Dev $131: 2-8$

White PA, Douglas GR, Gingerich J, Parfett C, Shwed P, Seligy V, Soper L, Berndt L, Bayley J, Wagner S et al (2003) Development and characterization of a stable epithelial cell line from Muta Mouse lung. Environ Mol Mutagen 42:166-184

Wijnhoven SW, Beems RB, Roodbergen M, van den Berg J, Lohman PH, Diderich K, van der Horst GT, Vijg J, Hoeijmakers JH, van Steeg H (2005) Accelerated aging pathology in ad libitum fed $\mathrm{Xpd}(\mathrm{TTD})$ mice is accompanied by features suggestive of caloric restriction. DNA Repair 4: 1314-1324

Wijnhoven SW, Hoogervorst EM, de Waard H, van der Horst GT, van Steeg H (2007) Tissue specific mutagenic and carcinogenic responses in NER defective mouse models. Mutat Res 614:77-94

Yang SH, Chang SY, Ren S, Wang Y, Andres DA, Spielmann HP, Fong LG, Young SG (2011) Absence of progeria-like disease phenotypes in knock-in mice expressing a non-farnesylated version of progerin. Hum Mol Genet 20:436-444 